\title{
Positive and Negative Regulation of the Virulence-Associated Coronafacoyl Phytotoxin in the Potato Common Scab Pathogen Streptomyces scabies
}

\author{
Zhenlong Cheng, Luke Bown, Brandon Piercey, and Dawn R.D. Bignell ${ }^{+}$ \\ Department of Biology, Memorial University of Newfoundland, St. John's, NL A1B 3X9, Canada
}

Accepted 17 May 2019.

\begin{abstract}
The potato common scab pathogen Streptomyces scabies produces $N$-coronafacoyl-L-isoleucine (CFA-Ile), which is a member of the coronafacoyl family of phytotoxins that are synthesized by multiple plant pathogenic bacteria. The CFA-Ile biosynthetic gene cluster contains a regulatory gene, $c f a R$, which directly controls the expression of the phytotoxin structural genes. In addition, a gene designated orf 1 encodes a predicted ThiF family protein and is cotranscribed with $c f a R$, suggesting that it also plays a role in the regulation of CFA-Ile production. In this study, we demonstrated that $\mathrm{CfaR}$ is an essential activator of coronafacoyl phytotoxin production, while ORF1 is dispensable for phytotoxin production and may function as a helper protein for CfaR. We also showed that CFA-Ile inhibits the ability of CfaR to bind to the promoter region driving expression of the phytotoxin biosynthetic genes and that elevated CFA-Ile production by overexpression of both $c f a R$ and orf1 in $S$. scabies increases the severity of disease symptoms induced by the pathogen during colonization of potato tuber tissue. Overall, our study reveals novel insights into the regulatory mechanisms controlling CFA-Ile production in S. scabies and it provides further evidence that CFAIle is an important virulence factor for this organism.
\end{abstract}

Keywords: genetics and gene regulation, phytotoxins and mycotoxins, secondary metabolism, toxins

Common scab (CS) is an important disease of potato (Solanum tuberosum) caused by several different plant pathogenic Streptomyces spp. (Wanner and Kirk 2015). The symptoms of the disease vary from superficial to deep-pitted or raised lesions that form on the surface of potato tubers, and, while these lesions do not affect the nutritional quality of the potatoes, they

Current address for Luke Bown: Carl R. Woese Institute for Genomic Biology, University of Illinois at Urbana-Champaign, 1206 W Gregory Drive, Urbana Il, 61801, U.S.A.

${ }^{\dagger}$ Corresponding author: D. R. D. Bignell; dbignell@mun.ca

Funding: This work was supported by a Natural Sciences and Engineering Research Council of Canada Discovery Grant number 386696-2010 to D. R. D. Bignell.

*The $\boldsymbol{e}$-Xtra logo stands for "electronic extra" and indicates that six supplementary figures and two supplementary tables are published online.

The author(s) declare no conflict of interest.

() 2019 The American Phytopathological Society have a negative impact on the tuber market value. In Canada, it has been estimated that CS caused losses of between $\$ 15.3$ and $\$ 17.3$ million Canadian in 2002 (Hill and Lazarovits 2005), and in Tasmania, Australia losses attributed to CS have been estimated at \$3.66 million Australian per acre, representing about $4 \%$ of the industry value (Wilson 2004). There is also evidence that CS can affect potato yields by causing delayed emergence of the tubers and decreased tuber sizes (Hiltunen et al. 2005).

The main pathogenicity factor produced by scab-causing Streptomyces spp. is a nitrated 2,5-diketopiperazine phytotoxin called thaxtomin A (King and Calhoun 2009). Pure thaxtomin A can induce necrosis on excised potato tuber tissue and can cause scab-like lesions on immature potato tubers (Bignell et al. 2010a). It has been noted that there is a positive correlation between thaxtomin A production and the pathogenicity of scab-causing Streptomyces spp. (Goyer et al. 1998; King et al. 1991; Kinkel et al. 1998; Loria et al. 1995) and thaxtomin A-deficient mutant strains do not cause typical disease symptoms (Healy et al. 2000). Although the exact function of thaxtomin $\mathrm{A}$ in plant pathogenicity is not clear, several lines of evidence suggest that it targets cellulose synthesis in the plant host (Bischoff et al. 2009; Duval and Beaudoin 2009; Fry and Loria 2002; Scheible et al. 2003) and may be required for the penetration of plant tissue during host colonization (Loria et al. 2008).

Recently, S. scabies was reported to be able to produce $\mathrm{N}$ coronafacoyl-L-isoleucine (CFA-Ile), which is a member of the coronafacoyl family of phytotoxins (Fyans et al. 2015). Coronafacoyl phytotoxins are known or suspected to be produced by several different plant-pathogenic bacteria, and, while they are not essential for the pathogenicity of the producing organisms, they typically enhance the severity of disease symptoms induced by these organisms (Bignell et al. 2018). The best-characterized coronafacoyl phytotoxin is coronatine (COR), which is an important virulence determinant produced by the gramnegative plant pathogen Pseudomonas syringae. COR contributes to pathogen invasion and persistence within plant tissues and to disease symptom development (Xin and He 2013). It functions as a molecular mimic of the plant hormone jasmonoyl-L-isoleucine (JA-Ile), and production of COR within the plant host leads to both activation of JAmediated signaling and suppression of salicylic acid (SA)mediated signaling (Xin and He 2013). This, in turn, results in suppression of the plant immune responses that are important for combating $P$. syringae infection (Katsir et al. 2008). CFA-Ile and other coronafacoyl phytotoxins exhibit similar bioactivities against plant tissues as COR, suggesting that they may also function as molecular mimics of JA-Ile (Bignell et al. 2018). A mutant of S. scabies unable to 
produce CFA-Ile was previously shown to cause less-severe disease symptoms in a tobacco seedling bioassay, though the organism was still pathogenic (Bignell et al. 2010b). While this suggests that CFA-Ile production contributes to the virulence phenotype of $S$. scabies, it is currently unclear whether one or both the development and severity of CS disease symptoms caused by $S$. scabies is affected by production of this phytotoxin.

The coronafacoyl phytotoxin biosynthetic gene cluster in S. scabies is composed of at least 15 genes (Fig. 1), of which 13 are cotranscribed as a single polycistronic mRNA and encode the enzymes required for phytotoxin biosynthesis (Bignell et al. $2010 b$ ). Another gene called $c f a R$ is divergently transcribed from the biosynthetic operon and encodes a cluster-situated regulator (CSR) that directly controls the expression of the phytotoxin biosynthetic genes (Bignell et al. 2010b; Cheng et al. 2015). CfaR is a 265-amino acid protein belonging to the PAS-LuxR family of transcriptional regulators, which are widely distributed among actinomycete bacteria (Bignell et al. 2014a) Expression of the CFA-Ile biosynthetic genes and production of CFA-Ile is induced by overexpression of $\mathrm{CfaR}$, indicating that $\mathrm{CfaR}$ is a positive activator of the CFA-Ile biosynthetic pathway (Bignell et al. 2010b; Cheng et al. 2015). CfaR binds to a single site within the promoter region that drives expression of the biosynthetic operon, and this binding activity requires both the LuxR DNA-binding domain and the PAS domain, the latter of which is involved in protein homodimer formation (Cheng et al. 2015). Expression of $c f a R$ itself is controlled by at least three pleiotropic regulators that also control the expression of other phytotoxin biosynthetic genes in S. scabies (Bignell et al. 2014b). Downstream of $c f a R$ is a second gene called orfl (also known as SCAB_79581), which encodes a 636-amino acid protein. orfl is cotranscribed with $c f a R$ (Bignell et al. 2010b) and overexpression of both $c f a R$ and orfl causes significantly greater CFA-Ile production in $S$. scabies as compared with overexpression of $c f a R$ alone (Cheng et al. 2015). These results suggest that orf1 may also function in the regulation of CFA-Ile production in $S$. scabies.

In this study, we employed a combination of genetic and biochemical approaches to further investigate the regulation of CFA-Ile biosynthesis in S. scabies. Our results show that CfaR is the principal regulator controlling CFA-Ile biosynthesis and that ORF1 is important but not essential for metabolite production and may serve as a helper protein in assisting the function of CfaR. We also demonstrate that CFA-Ile inhibits the DNA-binding activity of CfaR in vitro, suggesting that its production is subjected to negative feedback inhibition in $S$. scabies. We show that enhanced CFA-Ile production by overexpression of both $c f a R$ and orfl augments the severity of disease symptoms induced by $S$. scabies during colonization of potato tuber tissue. Altogether, our study provides important insights into the regulatory mechanisms controlling CFA-Ile production in $S$. scabies and it further supports the notion that CFA-Ile is an important virulence factor in this organism.

\section{RESULTS}

ORF1 is a member of the ThiF protein family.

The orfl gene is located downstream of $c f a R$ and encodes a predicted 636-amino acid protein. A search of the Pfam database generated two matches to known protein domains within the amino acid sequence. The region between amino acids 26 and 286 aligned with the ThiF family domain (THIF, PF00899) (Vander Horn et al. 1993), which is found in enzymes such as the eukaryotic ubiquitin-activating enzyme E1, the Escherichia coli thiamine biosynthetic enzyme ThiF, and the E. coli molybdenum cofactor biosynthetic enzyme MoeB (Leimkühler et al. 2001). A putative nitroreductase domain (TM1568_NiRdase, PF14512) (Bryant and DeLuca 1991) was detected in the region between amino acids 319 and 372 . BlastP analysis using the ORF1 amino acid sequence identified multiple homologs within the database and defined the ThiF domain between amino acids 55 and 177 within the ORF1 sequence. We chose 10 nonredundant ORF1 homologs which, when compared with ORF1, have $\geq 96 \%$ coverage and $\geq 59 \%$ amino acid identity for phylogenetic analysis (Supplementary Table S1). Six of the ORF1 homologs are encoded immediately next to genes encoding homologs of $\mathrm{CfaR}$ in the respective genome sequences (Fig. 2A) (Bown et al. 2017). In Streptomyces europaeiscabiei $96-14$, genes encoding homologs of both ORF1 and $\mathrm{CfaR}$ are also present, though the genes are not situated close to each other in the genome sequence of this organism. Phylogenetic analysis revealed that the ORF1 homologs form two distinct clades, of which clade I includes ORF1 itself as well as all the homologs that are encoded next to $c f a R$ homologs (Fig. 2A). Notably, the ORF1 homologs identified in other plantpathogenic Streptomyces spp. (S. europaeiscabiei and S. turgidiscabies) are located in clade II and, thus, do not cluster with ORF1 (Fig. 2A).

Members of the ThiF protein family are known to exhibit AMPylation (also known as adenylylation or adenylation) activity (Hershko and Ciechanover 1998; Lehmann et al. 2006; Leimkühler et al. 2001; Taylor et al. 1998; Vander Horn et al. 1993; Xi et al. 2001), which is the covalent attachment of AMP to a protein or other molecule through ATP hydrolysis (Itzen et al. 2011). A study by Regni and colleagues (2009) characterized the ATP-binding site of the ThiF family protein MccB from E. coli and they found that ATP binds within a cleft centered around an ATP-binding motif (GCGGIG). GCGGIG in $\mathrm{MccB}$ matches a well-known nucleotide binding motif, GXGXXG (Spitaler et al. 2000), and this binding motif along with other amino acids shown to interact with ATP is conserved in other ThiF family proteins, including ORF1 (Fig. 2B) (Regni et al. 2009). We built a three-dimensional (3D) model of the ORF1 protein based on the entire amino acid sequence, and the conserved amino acids associated with the proposed ATPbinding site form a 'pocket' within the predicted ORF1 structure (Supplementary Fig. S1) based on structural similarity to the $E$. coli ThiF protein (Duda et al. 2005). Further comparison of the predicted ATP-binding domain to that observed in MccB

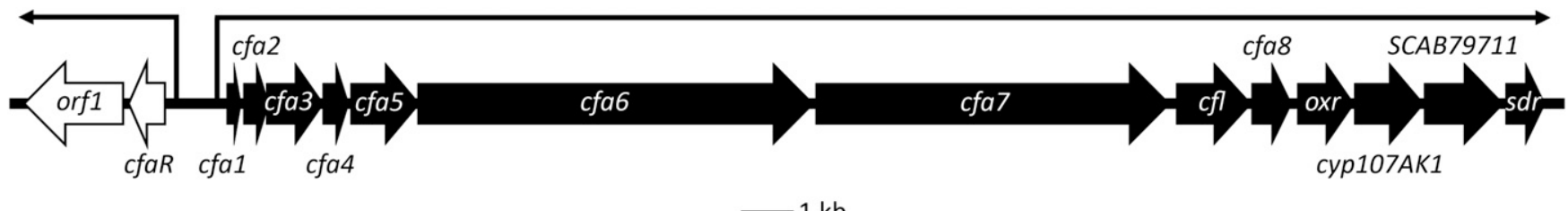

$1 \mathrm{~kb}$

Fig. 1. Organization of the coronafacoyl phytotoxin biosynthetic gene cluster in Streptomyces scabies 87-22. The block arrows denote the coding sequences within the cluster, and the direction of each arrow indicates the direction of transcription. The $c f a R$ gene encoding the PAS-LuxR family regulator and the downstream orf1 gene encoding a ThiF family protein are shown in white. Genes encoding biosynthetic enzymes (cfal-8, cfl, SCAB79711, cyp107AK1, sdr) are shown in black. The thin arrows shown above the gene cluster represent the two transcription units that have been identified. 
B

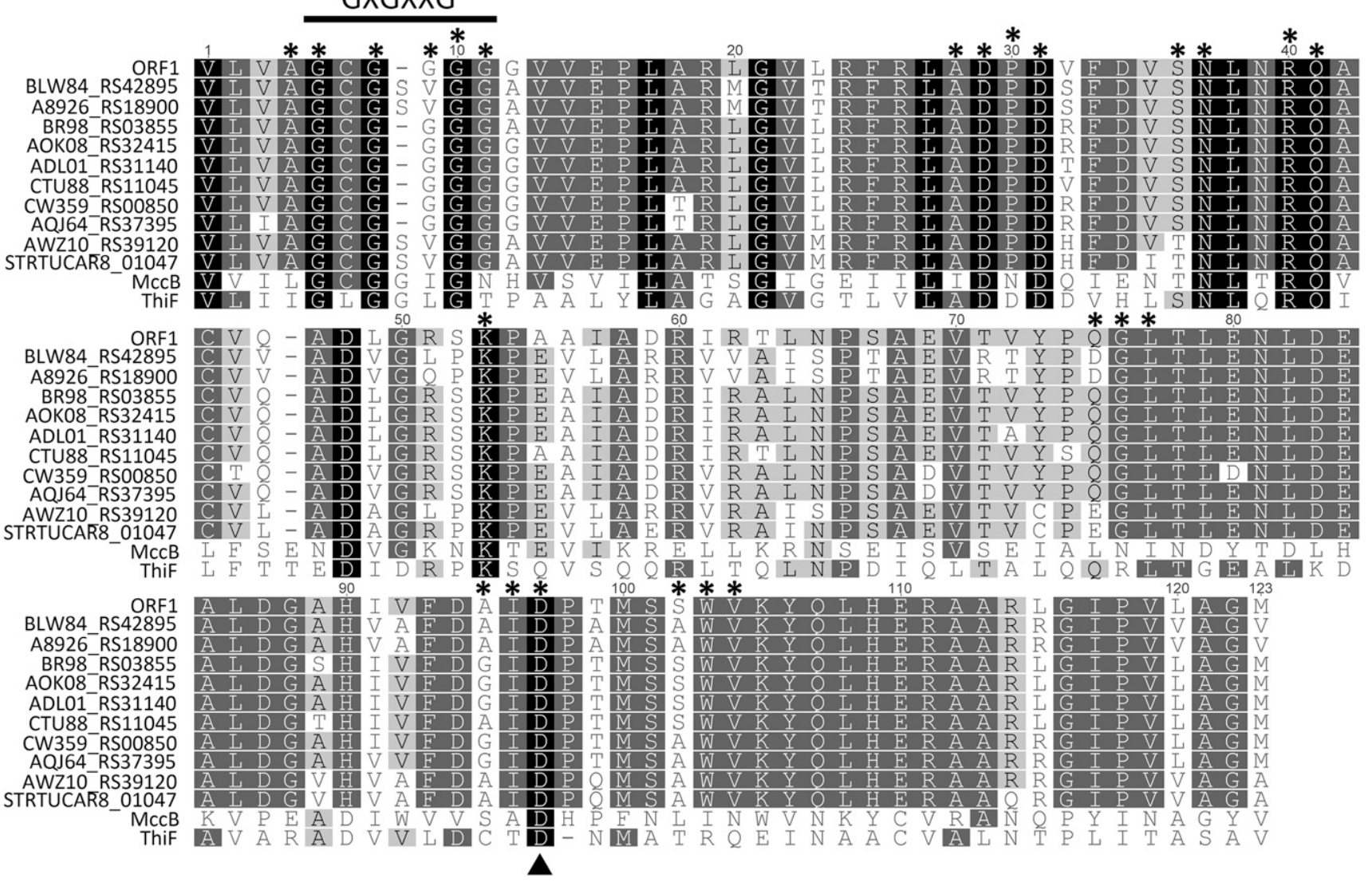

Fig. 2. Bioinformatics analysis of ORF1 and other ThiF family proteins from actinomycetes. A, Phylogenetic analysis of ORF1 homologs from the database. The evolutionary history was inferred using the maximum likelihood method based on the JTT matrix-based model (Jones et al. 1992). A discrete Gamma distribution was used to model evolutionary rate differences among sites. Bootstrap values $\geq 50 \%$ are shown at the respective branch points and are based on 1,000 repetitions. The scale bar indicates the number of nucleotide substitutions per site. The ThiF protein from Escherichia coli served as an outgroup. Two asterisks (**) indicate that the ORF1 homolog is encoded immediately next to a CfaR homolog within the respective genome, and one (*) indicates that the ORF1 homolog is encoded in a genome that also encodes a CfaR homolog but the genes are not situated next to each other. The two primary clades identified are indicated with I and II. B, Partial alignment of the ORF1 amino acid sequence with that of other ThiF family proteins. Sequences shown are truncated according to the ThiF domain of ORF1. The conserved GXGXXG nucleotide binding motif is labeled. Amino acids in ORF1 that are predicted to be involved in ATP binding, based on the proposed three-dimensional model of the protein as well as published structural analysis of ThiF and MccB, are indicated with the asterisks. The conserved aspartic acid residue, which, in $\mathrm{MccB}$, is involved in $\mathrm{Mg}^{2+}$ binding, is indicated by a black triangle $(\boldsymbol{\Lambda})$. Highly conserved amino acids in the alignment are highlighted as follows: black, 100\% identity; dark gray, 80 to $99 \%$ identity; light gray, 60 to $79 \%$ identity; and white, $<60 \%$ identity. 
corroborated the residue binding (Regni et al. 2009). $\mathrm{Mg}^{2+}$ is required for AMPylation catalyzed by MccB (Roush et al. 2008; Regni et al. 2009), and an aspartic acid residue (D214) involved in $\mathrm{Mg}^{2+}$ binding is also conserved in other ThiF family proteins, including ORF1 (Fig. 2B). Together, our analyses suggest that, like other ThiF family members, ORF1 may bind ATP and $\mathrm{Mg}^{2+}$ and may exhibit AMPylation activity toward one or more substrate molecules.

\section{ORF1 is a positive regulator}

of coronafacoyl phytotoxin production in S. scabies.

Previous work from our lab (Cheng et al. 2015) demonstrated that the production of CFA-Ile is greatly increased in $S$. scabies when the $c f a R$ CSR is overexpressed together with orfl as compared with when $c f a R$ is overexpressed on its own, whereas overexpression of orfl on its own has no effect on metabolite production. To confirm that the observed increase in metabolite production in the cfaR and cfaR+orfl overexpression strains is due to an increase in expression of the corresponding biosynthetic genes, semiquantitative reverse transcription (RT)-PCR was performed in order to examine the expression of the $c f a l$ gene, which is the first gene in the coronafacoyl phytotoxin biosynthetic operon (Bignell et al. 2010b). As shown in Figure 3, the transcription level of $c f a l$ was increased when $c f a R$ was overexpressed alone, and the expression level was even greater when $c f a R$ and orfl were both overexpressed. In contrast, the expression level of $c f a l$ as well as that of $c f a R$ and orfl was very low in the wild-type $S$. scabies and vector control strains (Fig. 3). We also noted that the expression level of $c f a R$ appeared to be increased when both $c f a R$ and orfl were overexpressed as compared with when $c f a R$ alone was overexpressed (Fig. 3). Thus, the results confirm that overexpression of orfl has a positive effect on the transcription of the coronafacoyl phytotoxin biosynthetic operon. Moreover, the results verify that the expression of the CFAIle biosynthetic and regulatory genes is very low in wild-type S. scabies 87-22, accounting for the low level of metabolite production by this strain under the culturing conditions used (Fyans et al. 2015).

To further study the role of the orfl gene in CFA-Ile biosynthesis, a deletion mutant was constructed in the S. scabies $\Delta t x t A$ strain, which is deficient in thaxtomin A production (Table 1). This particular strain was used because it was previously shown to produce elevated levels of CFAIle, as compared with S. scabies 87-22 (Fyans et al. 2015), and semiquantitative RT-PCR analysis confirmed that expression of the biosynthetic genes is higher in the $\Delta t x t A$ strain than in strain 87-22 (Supplementary Fig. S2). The $\Delta t x t A / \Delta$ orf 1 mutant was constructed and five independent mutant isolates were tested for CFA-Ile production. As shown in Figure 4A, the mutant isolates all produced significantly less CFA-Ile compared with the parental $\Delta t x t A$ strain, though production could still occur. On average, the CFA-Ile production level in the mutant isolates was only $27 \%$ of that observed in the parental strain. Furthermore, while deletion of orfl decreased CFA-Ile production, deletion of $c f a R$ or both $c f a R$ and orfl abolished metabolite production completely (Fig. 4B), indicating that $c f a R$ is an essential regulator of metabolite biosynthesis in $S$. scabies. Heterologous overexpression of the orfl gene in the $\Delta t x t A / \Delta$ orfl mutant isolate partially restored CFA-Ile production up to $59.6 \%$ of the level observed in the $\Delta t x t A$ parental strain (Supplementary Fig. S3), while $c f a R$ overexpression in the same strain was able to fully complement the mutant phenotype (Fig. 4C), suggesting that high expression of $c f a R$ is sufficient to compensate for the loss of orfl in $S$. scabies. Furthermore, overexpression of both $c f a R$ and orfl in the $\Delta t x t A / \Delta$ orfl mutant allowed for significantly higher
CFA-Ile production, as compared with the parental strain (Fig. 4C).

Together, our results show that $\mathrm{CfaR}$ is the principal regulator controlling CFA-Ile biosynthesis in S. scabies while ORF1 augments metabolite production but is not essential for production.

\section{CFA-Ile inhibits the DNA-binding activity of CfaR.}

The PAS domain within CfaR was previously shown to be involved in protein homodimer formation (Cheng et al. 2015), and it was predicted that it may also play a role in controlling the DNA-binding activity of the protein in response to a signal or small molecule ligand. As it is known that end products or intermediates of a biosynthetic pathway can interact with CSRs to control specialized metabolite production in Streptomyces spp. (Du et al. 2011; Jiang and Hutchinson 2006; Li et al. 2013, 2018; Mao et al. 2013; Niu et al. 2016; Tahlan et al. 2007; Xu et al. 2010), we hypothesized that CFA-Ile itself may function as a small molecule ligand for CfaR, and therefore, electrophoretic mobility shift assays (EMSAs) were performed to test the effect of CFA-Ile on the DNA-binding activity of CfaR. Purified CfaR$\mathrm{HIS}_{6}$ protein was incubated with its DNA target sequence in the presence of CFA-Ile and two related molecules, CFA (a biosynthetic intermediate of CFA-Ile) and COR (a structural analog of CFA-Ile) (Fig. 5A). Among the tested molecules, CFA-Ile was the only one that clearly inhibited the DNA-binding activity of CfaR in vitro (Fig. 5B). DNA-binding activity was slightly inhibited by equimolar amounts of CFA, while COR did not cause any inhibition (Fig. 5B). To further investigate the effect of CFAIle, EMSAs were repeated using different concentrations of the metabolite. The inhibition of CfaR-binding activity by CFA-Ile was found to occur in a concentration-dependent manner, and inhibition could be observed with as little as $0.7725 \mu \mathrm{M}$ CFA-Ile (Fig. 5C). Our results suggest that the activity of CfaR is negatively regulated by CFA-Ile, the end product of the biosynthetic pathway.

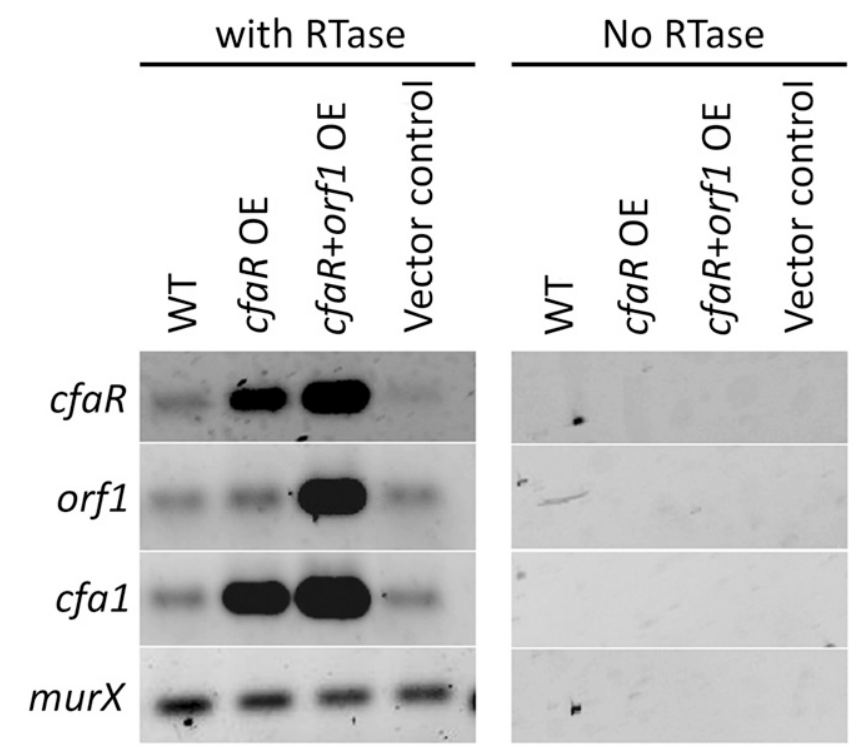

Fig. 3. Semiquantitative reverse transcription PCR analysis of gene expression in different Streptomyces scabies strains. Gene expression was analyzed in S. scabies 87-22 (WT), 87-22 containing the cfaR overexpression plasmid pRLDB51-1 ( $c f a R$ OE), 87-22 containing the $c f a R+o r f 1$ overexpression plasmid pRLDB891 (cfaR+orf1 OE) and 87-22 containing the plasmid vector pRLDB50-1a (vector control). Cultures were grown for $48 \mathrm{~h}$ in SFMB medium (Kieser et al. 2000), after which total RNA was extracted and was used as a template for reverse transcription reactions containing (with RTase) or lacking (no RTase) reverse transcription enzyme. Primers targeting the $c f a R$, orfl, cfal, and murX (loading control) genes were used in PCR reactions that were performed with $25(c f a R), 30$ (orfl and cfal) and 28 (murX) cycles. 
Elevated CFA-Ile production by $S$. scabies augments the severity of disease symptoms induced during colonization of potato tuber tissue.

CFA-Ile and other coronafacoyl phytotoxins have been shown to cause hypertrophy of potato tuber tissue (Fyans et al. 2015); however, it is currently unclear whether CFA-Ile production by $S$. scabies contributes directly or indirectly to CS disease development or disease symptom severity. In a tobacco seedling bioassay, a $S$. scabies $\Delta c f a 6$ mutant that was unable to produce CFA-Ile caused reduced stunting and necrosis of the tobacco seedling roots as compared with the wild-type strain. In contrast, no differences in the virulence phenotype of the wildtype and mutant strains was observed in a potato tuber bioassay (Bignell et al. 2010b). As wild-type $S$. scabies $87-22$ produces only trace levels of CFA-Ile in liquid culture (Fyans et al. 2015), it is possible that the lack of observable differences in virulence between strain 87-22 and the $\Delta c f a 6$ mutant may be due to the low level of CFA-Ile production by strain 87-22. S. scabies strains with varying CFA-Ile production levels generated in a previous study (Cheng et al. 2015) provided an opportunity to examine whether enhanced production of CFA-Ile leads to enhanced virulence. To test this hypothesis, we performed a potato tuber slice bioassay using four different $S$. scabies strains, namely i) wild-type 87-22, ii) wild-type vector control (87-22/pRLDB50-1a), iii) wild-type with $c f a R$ overexpression plasmid (87-22/pRLDB51-1), and iv) wild-type with $c$ faR+orf1 overexpression plasmid (87-22/pRLDB891). These strains were previously shown to produce varying amounts of CFA-Ile in liquid culture (wild type was equivalent to the vector control but was less than $c f a R$ overexpression, which was less than $c f a R+o r f l$ overexpression) (Cheng et al. 2015). The results of the bioassay revealed that the $c f a R$ and $c f a R+o r f 1$ overexpression strains caused greater necrosis and pitting of the potato tuber tissue when compared with the wild-type and vector control strains at all timepoints examined, with the cfaR+orfl overexpression strain causing the maximum amount of tissue damage (Table 2; Fig. 6). All the strains were shown to produce equivalent amounts of the essential virulence factor thaxtomin A in liquid culture, suggesting that the observed differences in disease severity are not simply due to differences in thaxtomin A production (Supplementary Fig. S4). We repeated the bioassay using strains that overexpress $c f a R$ and cfaR+orfl in the $\Delta t x t A$ thaxtomin A-deficient mutant, and we found that the $c f a R$ and $c f a R+o r f l$ overexpression strains were the only ones that caused observable hypertrophy of the potato tuber tissue, especially at the later timepoints (Table 2; Supplementary Fig. S5). The induction of tuber tissue hypertrophy is a well-documented effect attributed to coronafacoyl phytotoxin production (Bignell et al. 2018), and thus, our results confirm that the overexpression of $c f a R$ and $c f a R+o r f 1$ enhances the production of CFA-Ile during colonization of potato tuber tissue by $S$. scabies.

We noted that the amount of necrosis and pitting of the potato tuber tissue was greatest when the tissue was colonized by strains that produced high levels of CFA-Ile together with thaxtomin A (Fig. 6), suggesting that both phytotoxins are required for severe disease symptom development by $S$. scabies. However, when potato tuber tissue was treated with one or both pure thaxtomin A and CFA-Ile, the observed disease symptoms were not enhanced by the presence of both toxins versus thaxtomin A alone, suggesting that the effect of CFA-Ile is not mediated exclusively through synergistic interactions with thaxtomin A (Table 2; Supplementary Fig. S6).

\section{DISCUSSION}

Work presented in this study confirms that CfaR and ORF1 are both involved in the regulation of coronafacoyl phytotoxin production in S. scabies. Overexpression of the orfl gene together with $c f a R$ led to enhanced expression of the CFA-Ile biosynthetic genes as compared with overexpression of $c f a R$ alone (Fig. 3), while deletion of orfl in the $\triangle t x t A$ mutant background caused a significant decrease in CFA-Ile production, though production could still occur (Fig. 4A). In contrast, a $\Delta t x t A / \Delta c f a R$ mutant was completely abolished in CFA-Ile production (Fig. 4B) and overexpression of $c f a R$ alone

Table 1. Bacterial strains, plasmids, and cosmids used in this study

\begin{tabular}{|c|c|c|c|}
\hline Strain, plasmid, or cosmid & Description & Resistance $^{\mathrm{z}}$ & Reference or source \\
\hline \multicolumn{4}{|l|}{ Streptomyces scabies strains } \\
\hline $87-22$ & Wild-type strain & $\mathrm{n} / \mathrm{a}$ & Loria et al. 1995 \\
\hline$\Delta t x t A$ & $\begin{array}{l}87-22 \text { derivative containing a deletion of the } t x t A \text { thaxtomin } \\
\text { biosynthetic gene }\end{array}$ & Apra $^{R}$ & Johnson et al. 2009 \\
\hline$\Delta t x t A / \Delta o r f 1$ & $\Delta t x t A$ derivative containing a deletion of orfl gene & $\operatorname{Apra}^{R}, \mathrm{Hyg}^{\mathrm{R}}$ & This study \\
\hline$\Delta t x t A / \Delta c f a R$ & $\Delta t x t A$ derivative containing a deletion of the $c f a R$ gene & Apra $^{R}$, Hyg $^{R}$ & This study \\
\hline$\Delta t x t A / \Delta c f a R / \Delta o r f 1$ & $\Delta t x t A$ derivative containing a deletion of the $c f a R$ and orf 1 genes & Apra $^{R}$, Hyg $^{R}$ & This study \\
\hline \multicolumn{4}{|l|}{ Escherichia coli strains } \\
\hline NEB $5-\alpha$ & DH5 $\alpha$ derivative, high efficiency competent cells & $\mathrm{n} / \mathrm{a}$ & New England Biolabs \\
\hline ET12567/pUZ8002 & $\mathrm{dam}^{-}, \mathrm{dcm}^{-}, h s d S^{-}$; nonmethylating conjugation host & $\mathrm{Kan}^{\mathrm{R}}, \mathrm{Cam}^{\mathrm{R}}$ & MacNeil et al. 1992 \\
\hline BW25113/pIJ790 & Host strain for Redirect PCR targeting system & $\mathrm{Cam}^{\mathrm{R}}$ & Gust et al. 2003 \\
\hline \multicolumn{4}{|l|}{ Plasmid or cosmid } \\
\hline pIJ10700 & $\begin{array}{l}\text { Template for PCR amplification of the }[h y g+\text { oriT }] \text { cassette used } \\
\text { for Redirect PCR targeting }\end{array}$ & $\mathrm{Hyg}^{\mathrm{R}}$ & Gust et al. 2003 \\
\hline pRLDB50-1a & $\begin{array}{l}\text { Streptomyces expression plasmid derived from pLST9828; carries } \\
\text { the strong, constitutive ermE } \mathrm{p}^{*} \text { promoter and integrates into the } \\
\varphi \mathrm{C} 31 \mathrm{attB} \text { site }\end{array}$ & Apra $^{\mathrm{R}}$, Thio $^{\mathrm{R}}$ & Bignell et al. 2010b \\
\hline pRLDB51-1 & $c f a R$ overexpression plasmid derived from pRLDB50-1a & Apra $^{\mathrm{R}}$, Thio $^{\mathrm{R}}$ & Bignell et al. 2010b \\
\hline pRLDB891 & cfaR + orfl overexpression plasmid derived from pRLDB50-1a & Apra $^{\mathrm{R}}$, Thio $^{\mathrm{R}}$ & Cheng et al. 2015 \\
\hline pRLDB81 & orf1 overexpression plasmid derived from pRLDB50-1a & Apra $^{\mathrm{R}}$, Thio ${ }^{\mathrm{R}}$ & Cheng et al. 2015 \\
\hline Cosmid 158 & $\begin{array}{l}\text { SuperCos } 1 \text { derivative containing the } S \text {. scabies } 87-22 \text { CFA-Ile } \\
\text { biosynthetic gene cluster }\end{array}$ & $\mathrm{Amp}^{\mathrm{R}}, \operatorname{Kan}^{\mathrm{R}}$ & Bignell et al. $2010 \mathrm{~b}$ \\
\hline 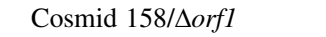 & Cosmid 158 derivative containing a deletion of the orfl gene & $\mathrm{Amp}^{\mathrm{R}}, \mathrm{Kan}^{\mathrm{R}}, \mathrm{Hyg}^{\mathrm{R}}$ & This study \\
\hline Cosmid $158 / \Delta c f a R$ & Cosmid 158 derivative containing a deletion of the $c f a R$ gene & $\mathrm{Amp}^{\mathrm{R}}, \mathrm{Kan}^{\mathrm{R}}, \mathrm{Hyg}^{\mathrm{R}}$ & This study \\
\hline Cosmid $158 / \Delta c f a R / \Delta o r f 1$ & Cosmid 158 derivative containing a deletion of the $c f a R$ and orfl genes & $\mathrm{Amp}^{\mathrm{R}}, \mathrm{Kan}^{\mathrm{R}}, \mathrm{Hyg}^{\mathrm{R}}$ & This study \\
\hline
\end{tabular}

${ }^{\mathrm{z}}$ Apra $^{\mathrm{R}}, \mathrm{Hyg}^{\mathrm{R}}, \mathrm{Thio}^{\mathrm{R}}, \mathrm{Kan}^{\mathrm{R}}, \mathrm{Cam}^{\mathrm{R}}$ and $\mathrm{Amp}^{\mathrm{R}}=$ apramycin, hygromycin, thiostrepton, kanamycin, chloramphenicol and ampicillin resistance, respectively. $\mathrm{n} / \mathrm{a}=$ not applicable. 
was able to compensate for the loss of ORF1 in the $\Delta t x t A / \Delta o r f 1$ mutant (Fig. 4C). Taken together, our results suggest that CfaR is the primary regulator controlling CFA-Ile biosynthetic gene expression and metabolite production, while ORF1 may

A

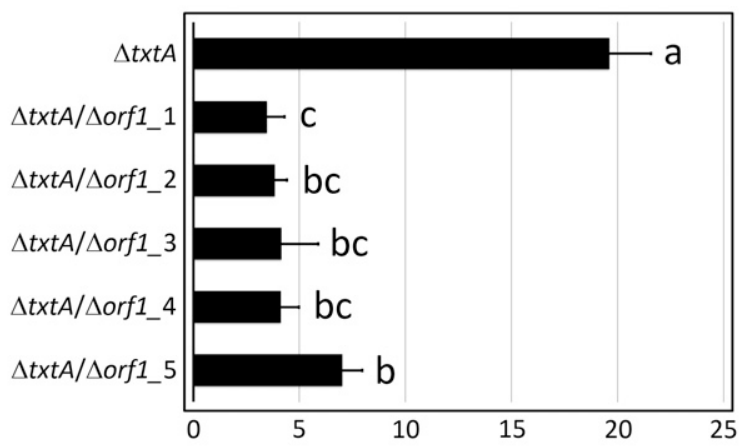

B

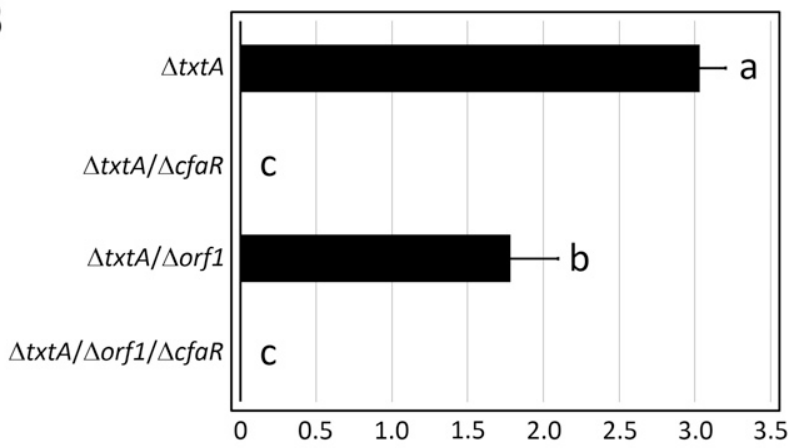

C

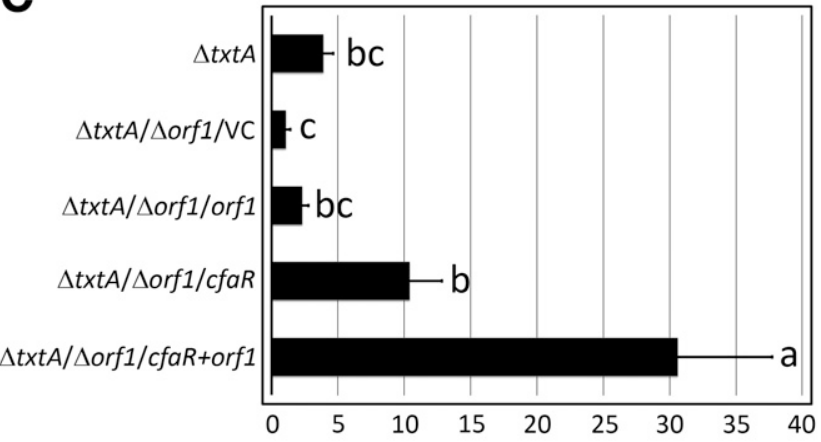

Normalized CFA-Ile Production Levels

(Peak area/mg DCW)

Fig. 4. Analysis of $N$-coronafacoyl-L-isoleucine (CFA-Ile) production in different Streptomyces scabies strains. A, Production of CFA-Ile by the $S$. scabies $\Delta t x t A$ parental strain and by the $\Delta t x t A / \Delta$ orfl mutant isolates. B, Production of CFA-Ile by the parental strain $S$. scabies $\triangle t x t A$ and by the $\Delta t x t A / \Delta c f a R, \Delta t x t A / \Delta o r f 1$, and $\Delta t x t A / \Delta c f a R / \Delta o r f 1$ mutant strains. C, Production of CFA-Ile by the $S$. scabies parental strain $\triangle$ txtA, the orfl mutant strain containing the plasmid vector pRLDB50-1a ( $\Delta$ txtA/ $\Delta$ orf1/VC [vector control]), the orfl mutant strain containing the orfl overexpression plasmid

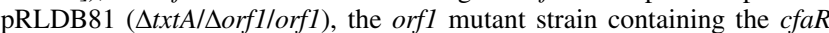

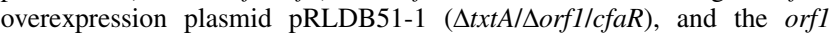
mutant strain containing the $c f a R+o r f 1$ overexpression plasmid pRLDB891 $(\Delta t x t A / \Delta o r f 1 / c f a R+o r f 1)$. Strains were cultured in SFMB medium (Kieser et al. 2000) for 7 days at $25^{\circ} \mathrm{C}$, after which the culture supernatants were harvested and were extracted with chloroform. The organic extracts were dried and redissolved in $100 \%(\mathrm{vol} / \mathrm{vol})$ methanol $+0.1 \%$ ( $\mathrm{vol} / \mathrm{vol})$ formic acid and were analyzed for CFA-Ile by high-pressure liquid chromatography. Shown is the mean normalized CFA-Ile production level (peak area per milligram of dry cell weight $[\mathrm{DCW}]) \pm$ standard deviation $(n=3)$ for each strain. Mean production levels in each experiment that do not share a letter are significantly different $(P \leq 0.05)$. function as a nonessential helper protein by augmenting CFAIle production in a CfaR-dependent manner. It is noteworthy that the involvement of regulatory proteins with 'helper activity' in controlling the production of specialized metabolites has been observed in other Streptomyces spp. For example, in Streptomyces fradiae, the nonessential TylU regulator has been proposed to assist the essential TylS regulator in activating expression of $t y l R$, which directly controls the expression of the tylosin biosynthetic genes (Bate et al. 2006). Similarly, the PapR1 protein, which is nonessential for pristinamycin production in Streptomyces pristinaespiralis, is thought to serve as a helper protein for the essential regulator PapR2 (Mast et al. 2015). Given that $c f a R$ and orf1 gene pairs are conserved in other Streptomyces spp. (Fig. 2A) (Bown et al. 2017), it is likely that the involvement of these genes in the regulation of metabolite production is not limited to $S$. scabies.

ORF1 shares similarity with members of the ThiF protein family that are known to function as AMPylators. For example, the founding member of the family is the E. coli ThiF protein, which is involved in the biosynthesis of thiamine by catalyzing the AMPylation of the carboxy terminus of the intermediate sulfur carrier ThiS (Lehmann et al. 2006; Vander Horn et al. 1993; Xi et al. 2001). MoeB is another ThiF family member that functions in molybdopterin biosynthesis by catalyzing the AMPylation of the MoaD subunit of molybdopterin synthase (Leimkühler et al. 2001). In E. coli, MccB catalyzes adenylation of MccA during the biosynthesis of microcin C7 (MccC7) (Regni et al. 2009). ORF1 also shows similarity to ubiquitin-activating E1 family proteins, which catalyze the formation of a ubiquitin adenylate during the

\section{A}
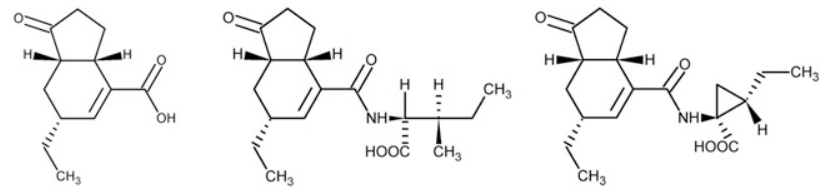

CFA

CFA-Ile

COR
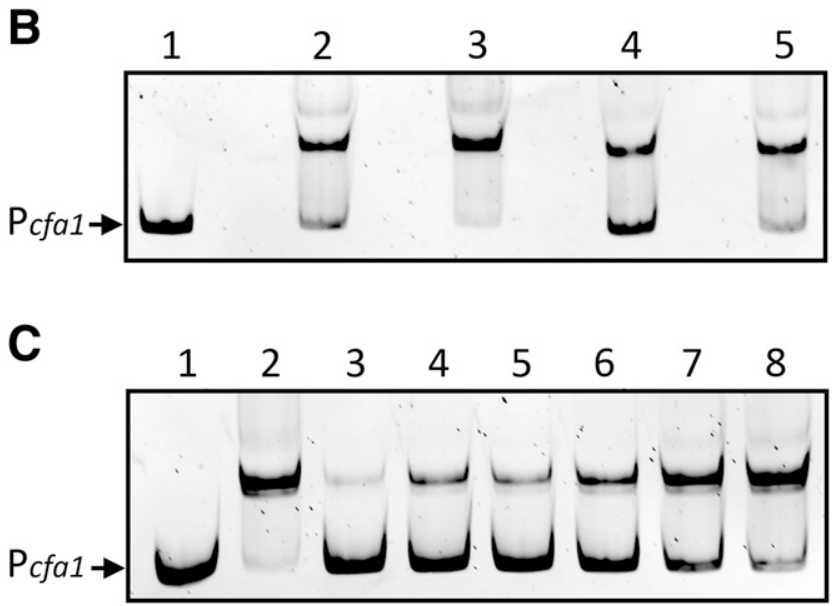

Fig. 5. $N$-coronafacoyl-L-isoleucine (CFA-Ile) inhibits the DNA-binding activity of CfaR. A, Structure of CFA, CFA-Ile, and coronatine (COR). B, CfaR-HIS $_{6}$ was incubated with the target DNA $\left(\mathrm{P}_{c f a l}\right)$ in the presence of CFA (lane 2), COR (lane 3), CFA-Ile (lane 4), and dimethyl sulfoxide (lane $5)$, after which the binding reactions were subjected to polyacrylamide gel electrophoresis. The control reaction (lane 1) lacked added CfaR-HIS protein. $\mathbf{C}$, Binding reactions were performed in the presence of different concentrations of CFA-Ile. The final concentration of CFA-Ile used (micromolar) are as follows: 0 (lane 2), 6.18 (lane 3), 3.09 (lane 4), 1.545 (lane 5), 0.7725 (lane 6), 0.38625 (lane 7), and 0.193125 (lane 8). The control reaction (lane 1) lacked added CfaR-HIS 6 protein. 
activation of ubiquitin in eukaryotes (Hershko and Ciechanover 1998). The conservation of amino acids shown to be involved in binding to ATP and $\mathrm{Mg}^{2+}$ in other AMPylators are conserved in ORF1 (Fig. 2B), suggesting that ORF1 may also function as an AMPylator. While we predicted that CfaR may be a target for AMPylation by ORF1, studies conducted in our lab have, so far, been unable to demonstrate this (data not shown). Thus, further work is needed to determine whether ORF1 is an AMPylator and to identify the target of such activity.

The CfaR regulator contains an N-terminal PAS domain, which, in other proteins, has been reported to function as a sensor domain and has the potential to bind small molecule ligands (Taylor and Zhulin 1999). We hypothesized that the final product of the coronafacoyl phytotoxin biosynthetic pathway, CFA-Ile, may function as a ligand for CfaR and regulate its activity, since it is known that intermediates and end products of specialized metabolite biosynthesis can function as ligands for some CSRs in other Streptomyces spp. (Du et al. 2011; Jiang and Hutchinson 2006; Li et al. 2013, 2018; Mao et al. 2013; Niu et al. 2016; Tahlan et al. 2007; Xu et al. 2010).

Table 2. Quantification of tissue damage induced by Streptomyces scabies strains or pure phytotoxins on potato tuber disks

\begin{tabular}{|c|c|c|}
\hline Strain or phytotoxin ${ }^{y}$ & $\begin{array}{c}\text { Days of } \\
\text { incubation }\end{array}$ & Mean $\operatorname{area}^{\mathrm{z}}$ \\
\hline \multicolumn{3}{|l|}{ Wild-type strains } \\
\hline $87-22$ & 2 & $5.1 \pm 3.0 \mathrm{~B}$ \\
\hline $87-22 / c f a R$ OE & 2 & $5.9 \pm 2.2 \mathrm{~B}$ \\
\hline 87-22/cfaR+orf1 OE & 2 & $18.1 \pm 5.6 \mathrm{~A}$ \\
\hline $87-22 / \mathrm{VC}$ & 2 & $3.2 \pm 1.6 \mathrm{~B}$ \\
\hline $87-22$ & 4 & $9.3 \pm 5.1 \mathrm{~B}$ \\
\hline $87-22 / c f a R$ OE & 4 & $11.7 \pm 0.5 \mathrm{AB}$ \\
\hline 87-22/cfaR+orf1 OE & 4 & $21.7 \pm 2.0 \mathrm{~A}$ \\
\hline $87-22 / \mathrm{VC}$ & 4 & $7.2 \pm 4.2 \mathrm{~B}$ \\
\hline $87-22$ & 7 & $9.1 \pm 1.2 \mathrm{C}$ \\
\hline $87-22 / c f a R$ OE & 7 & $21.3 \pm 3.9 \mathrm{~B}$ \\
\hline 87-22/cfaR+orf1 OE & 7 & $32.4 \pm 3.5 \mathrm{~A}$ \\
\hline $87-22 / \mathrm{VC}$ & 7 & $6.3 \pm 1.9 \mathrm{C}$ \\
\hline $87-22$ & 10 & $14.0 \pm 6.4 \mathrm{~B}$ \\
\hline $87-22 / c f a R$ OE & 10 & $32 \pm 13.6 \mathrm{AB}$ \\
\hline 87-22/cfaR+orf1 OE & 10 & $46.6 \pm 6.9 \mathrm{~A}$ \\
\hline $87-22 / \mathrm{VC}$ & 10 & $13.9 \pm 4.2 \mathrm{~B}$ \\
\hline \multicolumn{3}{|l|}{ Thaxtomin mutant strains } \\
\hline$\Delta t x t A$ & 2 & $1.0 \pm 1.5 \mathrm{~A}$ \\
\hline$\Delta t x t A / c f a R \mathrm{OE}$ & 2 & $1.8 \pm 0.6 \mathrm{~A}$ \\
\hline$\Delta t x t A / c f a R+o r f 1 \mathrm{OE}$ & 2 & $2.9 \pm 1.0 \mathrm{~A}$ \\
\hline$\Delta t x t A / \mathrm{VC}$ & 2 & $1.6 \pm 0.9 \mathrm{~A}$ \\
\hline$\Delta t x t A$ & 4 & $2.4 \pm 2.6 \mathrm{~A}$ \\
\hline$\Delta t x t A / c f a R \mathrm{OE}$ & 4 & $7.1 \pm 5.6 \mathrm{~A}$ \\
\hline$\Delta t x t A / c f a R+o r f 1 \mathrm{OE}$ & 4 & $8.7 \pm 4.3 \mathrm{~A}$ \\
\hline$\Delta t x t A / \mathrm{VC}$ & 4 & $4.1 \pm 3.0 \mathrm{~A}$ \\
\hline$\Delta t x t A$ & 7 & $3.3 \pm 2.9 \mathrm{~B}$ \\
\hline$\Delta t x t A / c f a R \mathrm{OE}$ & 7 & $6.9 \pm 0.9 \mathrm{~B}$ \\
\hline$\Delta t x t A / c f a R+o r f 1 \mathrm{OE}$ & 7 & $17.9 \pm 4.3 \mathrm{~A}$ \\
\hline$\triangle t x t A / \mathrm{VC}$ & 7 & $2.1 \pm 1.5 \mathrm{~B}$ \\
\hline$\Delta t x t A$ & 10 & $1.1 \pm 0.5 \mathrm{~B}$ \\
\hline$\Delta t x t A / c f a R \mathrm{OE}$ & 10 & $8.0 \pm 4.5 \mathrm{AB}$ \\
\hline$\Delta t x t A / c f a R+o r f 1 \mathrm{OE}$ & 10 & $22.6 \pm 10.5 \mathrm{~A}$ \\
\hline$\Delta t x t A / \mathrm{VC}$ & 10 & $0.5 \pm 0.7 \mathrm{~B}$ \\
\hline \multicolumn{3}{|l|}{ Phytotoxins } \\
\hline Thaxtomin A (1 nmol) & 10 & $33.5 \pm 1.5 \mathrm{~A}$ \\
\hline $\begin{array}{l}\text { Thaxtomin A }(1 \mathrm{nmol})+\text { CFA-Ile } \\
\quad(100 \mathrm{nmol})\end{array}$ & 10 & $35.0 \pm 5.0 \mathrm{~A}$ \\
\hline
\end{tabular}

$\overline{\mathrm{y}} \mathrm{OE}=$ overexpression strain, $\mathrm{VC}=$ vector control. The measurements reported for wild-type strains and phytotoxins are of the mean area of tuber tissue necrosis and pitting and those reported for thaxtomin mutant strains are of the mean area of tuber tissue hypertrophy.

${ }^{\mathrm{z}}$ Mean area of tuber tissue necrosis, pitting, or hypertrophy reported as the mean in square millimeters of three replicates \pm standard deviation. For each bioassay, the values for a given incubation time that are accompanied by the same letter are not significantly different $(P>0.05)$.
Results presented here show that pure CFA-Ile is able to antagonize the DNA-binding activity of CfaR in vitro in a concentration-dependent manner (Fig. 5), suggesting that the activity of CfaR and the production of CFA-Ile is subject to negative feedback regulation in S. scabies. Neither the structural analog COR nor the biosynthetic intermediate CFA were able to strongly inhibit the activity of CfaR at equimolar amounts (Fig. 5), suggesting that the regulation of CfaR is highly specific for the end product of the biosynthetic pathway. Negative feedback regulation by biosynthetic intermediates or end products, or both, has been reported to control the production of antibiotic metabolites such as the sansanmycins ( $\mathrm{Li}$ et al. 2013), jadomycin (Zhang et al. 2013), auricin (Kutas et al. 2013), simocyclinone (Horbal et al. 2012), and nosiheptide (Li et al. 2018), and it has been speculated that this may serve as a strategy to control the levels of antibiotic produced in order to ensure that the producing organism is not inhibited by its own product (Li et al. 2013). To our knowledge, ours is the first report of a phytotoxic specialized metabolite being subjected to negative feedback regulation in a streptomycete, and it is the first instance of a PAS-LuxR family regulator that can sense the end product of the biosynthetic process that it regulates.

Another important finding from our study is the revelation that strains of $S$. scabies producing elevated levels of CFA-Ile can cause greater necrosis and pitting of potato tuber tissue compared with strains producing lower metabolite levels (Fig. 6), suggesting that there is a positive correlation between CFAIle production and disease symptom severity during infection of potato tubers. These results provide further supporting evidence that CFA-Ile is an important virulence factor that, together with thaxtomin A and other virulence factors, likely contributes to the severity of CS disease symptoms induced by S. scabies during infection. Our results are consistent with other studies that demonstrated that COR and other coronafacoyl phytotoxins enhance the severity of disease symptoms induced by plant-pathogenic microbes during infection (Bignell et al. 2018). COR is known to promote pathogen invasion and persistence within plant tissues, and it contributes directly to disease symptom development (Bignell et al. 2018). The primary function of COR is believed to be related to its ability to function as a molecular mimic of JA-Ile and to suppress SA-mediated plant defense responses through stimulation of JA signaling and consequent antagonistic crosstalk (Brooks et al. 2005; Geng et al. 2014). In addition, COR has been reported to suppress pathogen defense mechanisms in a SAindependent manner in Arabidopsis (Geng et al. 2012). Given the similarities in structure and bioactivity between CFA-Ile and COR, it is possible that CFA-Ile has similar functions as COR in mediating JA signaling, though this remains to be determined.

The results of our study together with previous studies enable us to propose a hypothetical model for the regulation of coronafacoyl phytotoxin production in S. scabies (Fig. 7). The expression of the essential regulatory gene $c f a R$ is known to be controlled by higher level pleiotropic regulators of the bld (bald) gene family (Bignell et al. 2010b, 2014b) and, possibly, by other regulators. BldD and BldG are predicted to indirectly activate $c f a R$ gene expression, while BldA is required for translation of the single TTA codon within the $c f a R$ coding sequence. Once produced, the CfaR protein binds as a homodimer to the $c f a l$ promoter region and activates expression of the biosynthetic operon. ORF1, as a helper protein, is proposed to somehow assist CfaR in activating biosynthetic gene expression and metabolite production, possibly by facilitating the binding of CfaR to the $c f a l$ promoter or by some other mechanism. Once the CFA-Ile 
end product reaches a critical concentration in vivo, the metabolite inhibits CfaR DNA-binding activity, thereby switching the pathway off. Thus, it is proposed that coronafacoyl phytotoxin production is subjected to both positive and negative regulation, most likely as a way to fine-tune production and ensure its proper timing during host-pathogen interactions. Whether any plant-derived signals are involved in modulating CFA-Ile biosynthesis remains to be determined and will be the focus of future studies, along with a more in-depth analysis of the mechanism of the proposed ORF1 helper activity.
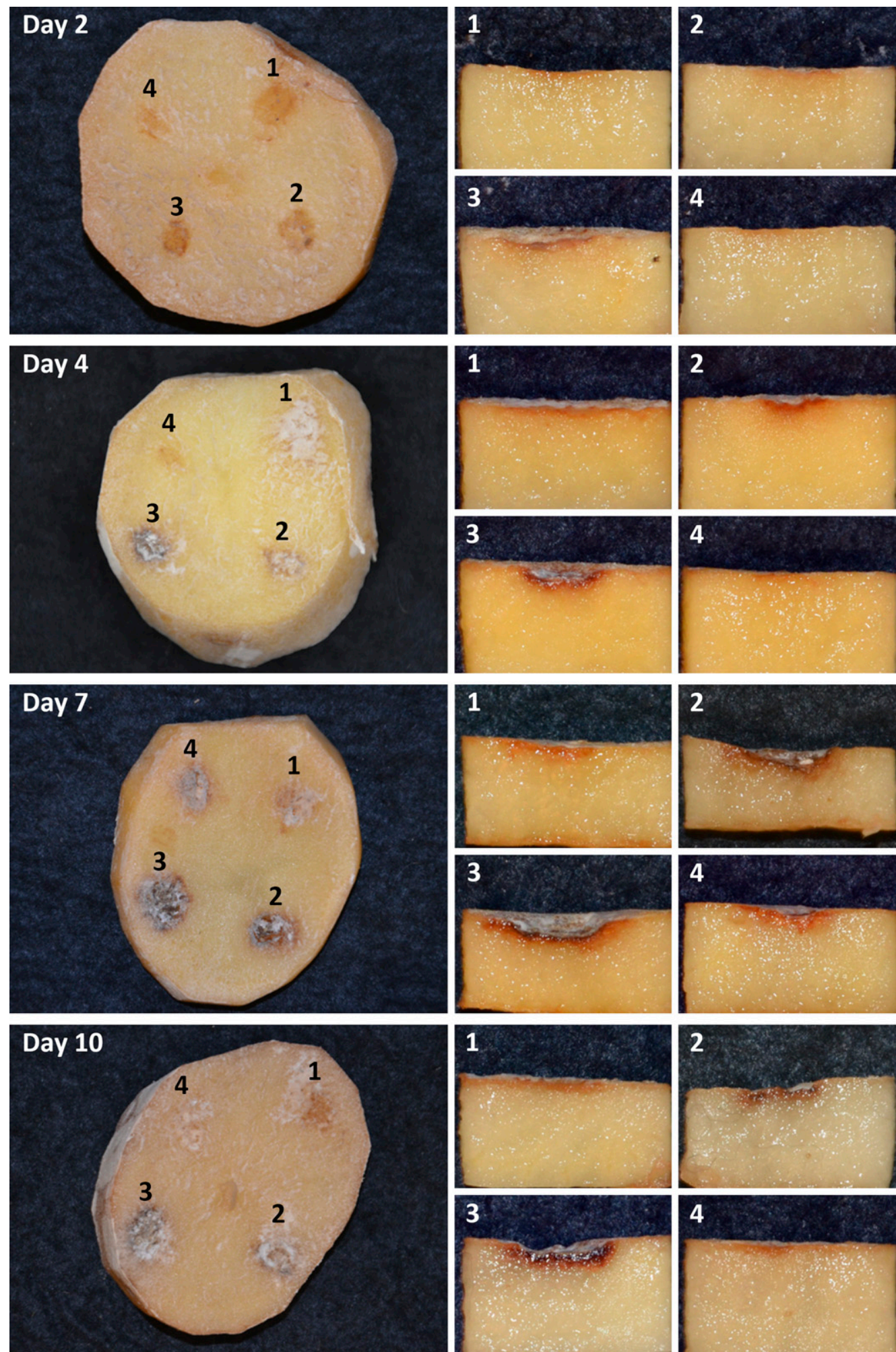

Fig. 6. Overexpression of $c f a R$ and orfl enhances the virulence phenotype of Streptomyces scabies 87-22. A potato tuber disk assay was performed using wildtype $S$. scabies 87-22, carrying no vector (1), cfaR overexpression plasmid pRLDB51-1 (2), cfaR+orf1 overexpression plasmid pRLDB891 (3), and control vector pRLDB50-1a (4). Photos were taken at 2, 4, 7, and 10 days postinoculation. The bioassay was performed three times, in total, with three replicates per treatment; representative results are shown. 


\section{MATERIALS AND METHODS}

Bacterial strains, cultivation, and maintenance.

Bacterial strains used in this study are listed in Table 1. E. coli strains were routinely cultivated in Luria-Bertani (LB) Lennox medium (Fisher Scientific) at $37^{\circ} \mathrm{C}$ unless otherwise stated. Where required, the LB medium was supplemented with kanamycin, apramycin, or chloramphenicol, as described previously (Cheng et al. 2015). E. coli strains were maintained at $-80^{\circ} \mathrm{C}$ in $20 \%$ (vol/vol) glycerol (Sambrook and Russell 2001).

Streptomyces strains were routinely cultured at $28^{\circ} \mathrm{C}$ on potato mash agar (PMA) (Fyans et al. 2015) for sporulation and maintenance. When necessary, the growth medium was supplemented with apramycin (final concentration of $50 \mu \mathrm{g} / \mathrm{ml}$ ), kanamycin $(50 \mu \mathrm{g} / \mathrm{ml})$, hygromycin B $(50 \mu \mathrm{g} / \mathrm{ml})$, or thiostrepton $(25 \mu \mathrm{g} / \mathrm{ml})$. For analysis of thaxtomin A or CFA-Ile production, seed cultures of $S$. scabies strains were prepared by inoculating $50 \mu \mathrm{l}$ of a frozen spore stock, $1 \mathrm{ml}$ of a mycelial stock, or fresh spores from a PMA plate into $5 \mathrm{ml}$ of trypticase soy broth (TSB) (BD Biosciences) in a 50-ml spring flask. The seed cultures were incubated at $28^{\circ} \mathrm{C}$ for 24 to $48 \mathrm{~h}$ with shaking (200 rpm) until dense mycelial growth was obtained, after which, they were subcultured (1 to $2 \%$ (vol/vol) inoculum) into $3 \times 5 \mathrm{ml}$ of oat bran broth (OBB) (Johnson et al. 2007) or SFMB (Kieser et al. 2000) in 6-well tissue culture plates for production of thaxtomin A or CFA-Ile, respectively. The cultures were incubated at $25^{\circ} \mathrm{C}$ with shaking (125 rpm) for 7 days prior to processing for metabolite analysis. For gene expression analysis, $S$. scabies TSB seed cultures $(0.5 \mathrm{ml})$ were subcultured into $25 \mathrm{ml}$ of SFMB in a $125-\mathrm{ml}$ spring flask. The cultures were then incubated at $25^{\circ} \mathrm{C}$ and $200 \mathrm{rpm}$ for $48 \mathrm{~h}$, after which, the mycelia were harvested for RNA isolation. S. scabies strains were maintained at $-80^{\circ} \mathrm{C}$ as spore suspensions in $20 \%$ (vol/vol) glycerol (Kieser et al. 2000) or as mycelial suspensions in TSB containing $25 \%$ glycerol (Shepherd et al. 2010).

\section{Plasmids, primers, and DNA manipulation.}

Plasmids and cosmids used in this study are listed in Table 1 and were manipulated in E. coli using standard procedures (Sambrook and Russell 2001). Standard desalted oligonucleotides used for PCR, RT-PCR, and DNA sequencing were purchased from Integrated DNA Technologies and are listed in Supplementary Table S2. All PCR-amplified genes in this study were verified by sequencing at The Centre for Applied Genomics.

\section{Bioinformatic analyses.}

BlastP was performed using the ORF1 amino acid sequence to identify homologous proteins in the database. Conserved domains within the ORF1 sequence were identified using BlastP and Pfam. Alignment of the ORF1 amino acid sequence with that of other ThiF family proteins was performed using ClustalW within the Geneious version 6.1.2 software (Biomatters Ltd.). The alignment was used to construct a phylogenetic tree in MEGA version 7.0.14 (Tamura et al. 2011), using the maximum likelihood method based on the JTT matrix-based model (Jones et al. 1992). A discrete Gamma distribution was used to model evolutionary rate differences among sites. The significance of the branch order in the tree was tested using the bootstrapping method (Felsenstein 1985) with 1,000 replicates.

The monomeric 3D model of ORF1 was produced using the default parameters of I-TASSER v5.1 (Roy et al. 2012; Zhang 2008). The resultant model was then visualized in PyMOL (v2.0.1) (Schrödinger, LLC.). The structural model was analyzed using COFACTOR and $\mathrm{COACH}$ to identify putative ligands that might interact with ORF1 (Roy et al. 2012; Yang et al. 2013; Zhang et al. 2017).

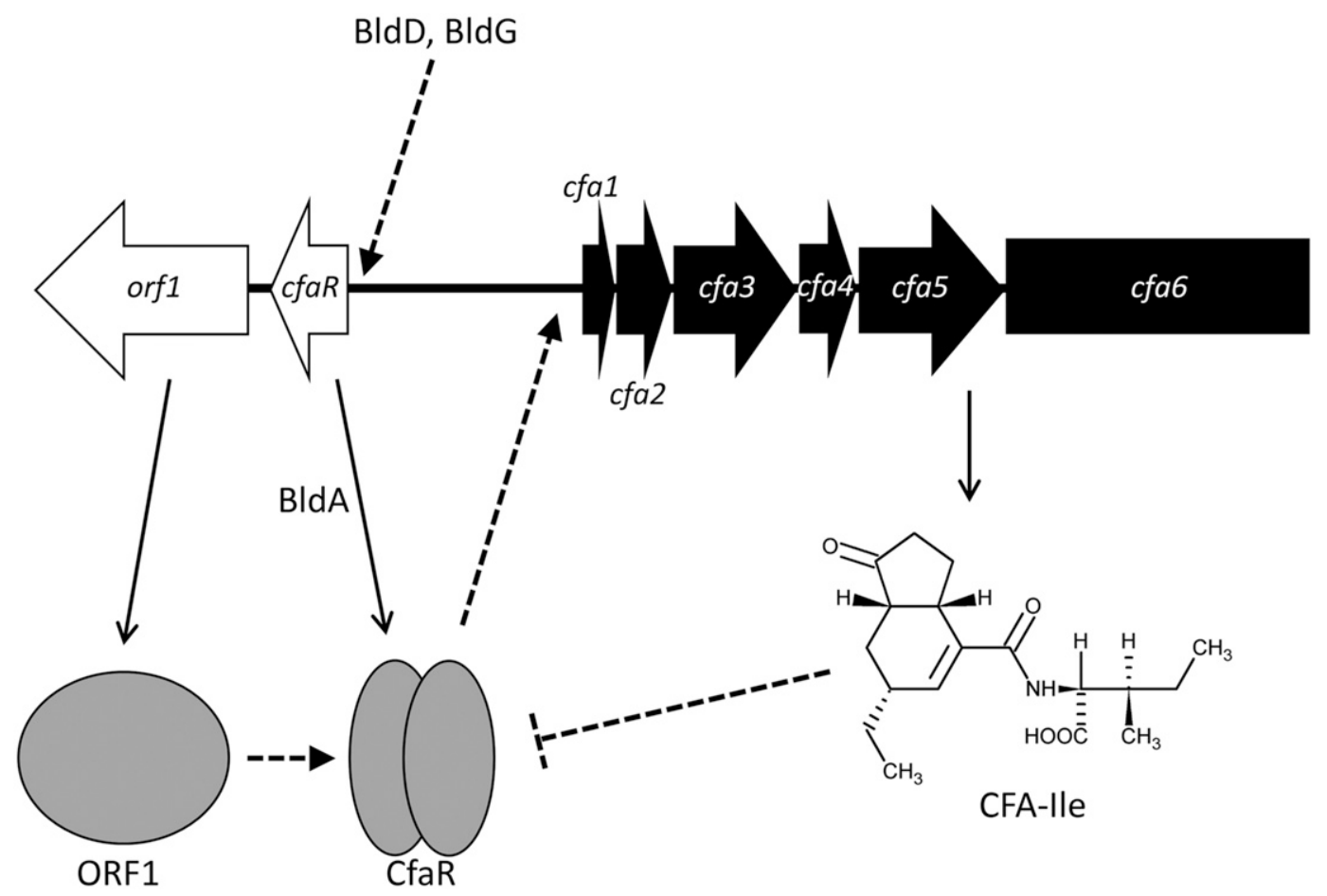

Fig. 7. Hypothetical model of the regulation of coronafacoyl phytotoxin production in Streptomyces scabies. The BldD and BldG pleiotropic regulators are predicted to indirectly activate transcription of the $c f a R$ gene, while the BldA pleiotropic regulator is required for production of the CfaR protein. CfaR dimerizes and binds to a single site within the $c f a l$ promoter region to activate expression of the metabolite structural genes, and this is somehow facilitated by the ORF1 protein. Accumulation of the $N$-coronafacoyl-L-isoleucine (CFA-Ile) end product leads to inhibition of CfaR DNA-binding activity and downregulation of the metabolite structural genes. Dashed arrows indicate transcriptional activation, whereas the dashed perpendicular line represents repression. Only the first six structural genes in the biosynthetic operon are shown. 


\section{RNA isolation and analysis of gene expression.}

Total RNA isolation from $S$. scabies mycelia was performed as described before (Cheng et al. 2015). Semiquantitative RTPCR analysis of gene expression was performed as described previously (Cheng et al. 2015), except that the RT step was conducted using random hexamer primers as per the manufacturer's instructions (Invitrogen). To ensure that any observed amplification was not due to the presence of contaminating genomic DNA in the RNA samples, the PCR reactions were performed using RT reactions that contained or lacked the RT enzyme. The resulting PCR products were analyzed by electrophoresis on a $1.2 \%(\mathrm{wt} / \mathrm{vol})$ agarose gel and $1 \times$ Tris-borate EDTA buffer and were visualized by staining with ethidium bromide.

\section{Construction of the $S$. scabies $\Delta t x t A / \Delta o r f 1, \Delta t x t A / \Delta c f a R$,} and $\Delta t x t A / \Delta c f a R / \Delta o r f 1$ mutant strains.

Gene deletion mutants were constructed using the Redirect PCR targeting system (Gust et al. 2003). Cosmid 158, harboring the $c f a R$ and orfl genes (Table 1), was electroporated into E. coli BW25113/pIJ790. The deletion cassettes were PCR-amplified using pIJ10700 as the template and using primers DRB292 and DRB293 for deletion of $c f a R$, JS1 and JS2 for deletion of orf1, and JS1 and DRB293 for deletion of $c f a R+o r f 1$. The PCR products were gel-purified and were then electroporated into arabinose-induced $E$. coli BW25113/pIJ790/Cosmid 158 that was cultured at $28^{\circ} \mathrm{C}$. The resulting mutant cosmids were verified by PCR (data not shown) and were then introduced into the $S$. scabies $\Delta t x t A$ mutant by conjugation with $E$. coli as described previously (Kieser et al. 2000). Exconjugants were selected for resistance to hygromycin $\mathrm{B}$ and sensitivity to kanamycin, and deletion of one or more target genes in the mutant isolates was confirmed by PCR (data not shown).

\section{Genetic complementation of the orf1 deletion mutant.}

The orfl overexpression plasmid pRLDB81, the $c f a R$ overexpression plasmid pRLDB51-1, and the cfaR+orf1 overexpression plasmid pRLDB891 (Table 1) were each introduced into the $\Delta t x t A / \Delta$ orf 1 mutant strain by conjugation with $E$. coli. As a control, the empty vector pRLDB50-1a (Table 1) was also introduced into the strain. The resulting exconjugants were selected by culturing on media containing thiostrepton.

\section{Detection of CFA-Ile production by $\boldsymbol{S}$. scabies strains.}

Small-scale extraction and high-performance liquid chromatography (HPLC) detection of CFA-Ile from S. scabies culture supernatants was as described before (Fyans et al. 2015). Triplicate samples originating from three independent cultures for each strain were used, and the area of the CFA-Ile peak detected in each sample was obtained using ChemStation software (B.04.03) (Agilent Technologies). Dry cell weights (DCWs) from metabolite production cultures were determined by harvesting the mycelia by centrifugation, drying the mycelial pellets for $24 \mathrm{~h}$ at $50^{\circ} \mathrm{C}$, and then, weighing the pellets using an analytical balance. The normalized CFA-Ile production levels were reported as peak area (counts $\mathrm{x}$ milliseconds) per milligram DCW.

\section{Detection of thaxtomin A production by $\boldsymbol{S}$. scabies strains.}

Small-scale extraction and HPLC detection of thaxtomin A from $S$. scabies culture supernatants was as described before (Fyans et al. 2016). Triplicate samples originating from three independent cultures for each strain were used, and the ChemStation software was used to determine the peak area of the thaxtomin A detected in each sample. DCWs were measured for the metabolite production cultures as described above, and the normalized thaxtomin A production levels were reported as the peak area (counts $\mathrm{x}$ milliseconds) per milligram DCW.

\section{EMSAs.}

A DNA fragment containing the CfaR binding site in the cfal promoter region was PCR-amplified using primers DRB252 and DRB283 and was gel-purified as described before (Cheng et al. 2015). CFA-Ile was purified from $S$. scabies cultures as described previously (Fyans et al. 2015). Pure COR was purchased from Sigma Aldrich, and pure CFA was purchased from C.Bender (professor emerita, Department of Entomology and Plant Pathology, Oklahoma State University, Stillwater, OK, U.S.A.). All the metabolites were dissolved in dimethyl sulfoxide (DMSO). CfaR-HIS 6 protein was overexpressed in E. coli and was purified as described before (Cheng et al. 2015).

EMSAs were performed using the LightShift Chemiluminescent EMSA kit (Fisher Scientific) as described previously (Cheng et al. 2015), with the following modifications. A 20$\mu \mathrm{l}$ reaction contained CfaR-HIS ${ }_{6}(0.277 \mu \mathrm{M})$, test compound $(1.545 \mu \mathrm{M})$, and DNA probe $(6.294 \mathrm{nM})$. Control reactions were set up that either lacked the protein or contained DMSO solvent in place of the test compound. For examining the concentration-dependent effect of CFA-Ile on CfaR DNAbinding activity, different amounts of CFA-Ile in a total volume of $5 \mu \mathrm{l}$ (made up using DMSO) were added to binding reactions to obtain the following final concentrations of metabolite (micromolar): 0, 6.18, 3.09, 1.545, 0.7725, 0.38625 , and 0.193125 . Following incubation at room temperature for $20 \mathrm{~min}$, the reactions were subjected to electrophoresis on a $6 \%(\mathrm{wt} / \mathrm{vol})$ polyacrylamide gel, and DNA bands were visualized under UV light following staining with ethidium bromide.

\section{Potato tuber bioassays.}

Potato tuber bioassays were performed as described previously (Loria et al. 1995) with some modifications. Strains were plated onto PMA plates and were incubated at $28^{\circ} \mathrm{C}$ for 7 days, until the organisms were well-sporulated. Potatoes were purchased from the grocery store and were peeled and surfacesterilized for $10 \mathrm{~min}$ in $15 \%$ ( $\mathrm{vol} / \mathrm{vol}$ ) bleach (Chlorox) before being washed in sterile water. The tubers were aseptically cut horizontally into 1-cm-thick slices, which were then placed onto sterile Whatman filter paper (moistened with sterile water) in sterile glass petri dishes. Agar plugs $(7 \mathrm{~mm}$ diameter) from the PMA plates were obtained using the blunt end of 1-ml sterile pipette tips and were placed spore-side down onto the potato tuber slices. Uninoculated PMA medium served as a negative control. All strains were tested using the same tuber slice to eliminate variation among potatoes. To test the biological activity of pure CFA-Ile and thaxtomin A, sterile paper disks $(0.6 \mathrm{~cm}$ in diameter) were placed onto potato tuber slices, and either $100 \mathrm{nmol}$ of CFA-Ile, $1 \mathrm{nmol}$ of thaxtomin A (Sigma Aldrich), or both were added onto each paper disk. The petri dishes with the potato tuber slices were sealed with parafilm and were incubated at room temperature in the dark. Photos were taken at days $2,4,7$, and 10 postinoculation, and quantification of the observed tissue damage was performed by measuring the area of tissue necrosis, pitting, or hypertrophy in the photographs, using ImageJ software (Schneider et al. 2012). The bioassays were each performed three times in total, and three replicates were set up in each bioassay.

\section{Statistical analyses.}

Statistical analyses were conducted in Minitab 18, using oneway analyses of variance with a posteriori multiple comparisons of least squared means performed using the Tukey test. 
$P$ values $\leq 0.05$ were considered statistically significant in all analyses.

\section{ACKNOWLEDGMENTS}

The authors thank G. Díaz-Cruz for assistance with the quantification of tissue damage in the potato tuber bioassays, and the anonymous reviewers for their helpful comments and suggestions.

\section{AUTHOR-RECOMMENDED INTERNET RESOURCES}

BlastP website: https://blast.ncbi.nlm.nih.gov

Pfam website: http://pfam.xfam.org

\section{LITERATURE CITED}

Bate, N., Bignell, D. R. D., and Cundliffe, E. 2006. Regulation of tylosin biosynthesis involving 'SARP-helper' activity. Mol. Microbiol. 62: 148-156.

Bignell, D. R. D., Cheng, Z., and Bown, L. 2018. The coronafacoyl phytotoxins: Structure, biosynthesis, regulation and biological activities. Antonie van Leeuwenhoek 111:649-666.

Bignell, D. R. D., Francis, I. M., Fyans, J. K., and Loria, R. 2014b. Thaxtomin A production and virulence are controlled by several bld gene global regulators in Streptomyces scabies. Mol. Plant-Microbe Interact 27:875-885

Bignell, D. R. D., Fyans, J. K., and Cheng, Z. 2014a. Phytotoxins produced by plant pathogenic Streptomyces species. J. Appl. Microbiol. 116: 223-235.

Bignell, D. R. D., Huguet-Tapia, J. C., Joshi, M. V., Pettis, G. S., and Loria, R. 2010a. What does it take to be a plant pathogen: Genomic insights from Streptomyces species. Antonie van Leeuwenhoek 98:179-194.

Bignell, D. R. D., Seipke, R. F., Huguet-Tapia, J. C., Chambers, A. H., Parry, R. J., and Loria, R. 2010b. Streptomyces scabies 87-22 contains a coronafacic acid-like biosynthetic cluster that contributes to plantmicrobe interactions. Mol. Plant-Microbe Interact 23:161-175.

Bischoff, V., Cookson, S. J., Wu, S., and Scheible, W. R. 2009. Thaxtomin A affects CESA-complex density, expression of cell wall genes, cell wall composition, and causes ectopic lignification in Arabidopsis thaliana seedlings. J. Exp. Bot. 60:955-965.

Bown, L., Li, Y., Berrué, F., Verhoeven, J. T. P., Dufour, S. C., and Bignell, D. R. D. 2017. Coronafacoyl phytotoxin biosynthesis and evolution in the common scab pathogen Streptomyces scabies. Appl. Environ. Microbiol. 83:e01169-17.

Brooks, D. M., Bender, C. L., and Kunkel, B. N. 2005. The Pseudomonas syringae phytotoxin coronatine promotes virulence by overcoming salicylic acid-dependent defences in Arabidopsis thaliana. Mol. Plant Pathol. 6:629-639.

Bryant, C., and DeLuca, M. 1991. Purification and characterization of an oxygen-insensitive NAD(P)H nitroreductase from Enterobacter cloacae. J. Biol. Chem. 266:4119-4125.

Cheng, Z., Bown, L., Tahlan, K., and Bignell, D. R. D. 2015. Regulation of coronafacoyl phytotoxin production by the PAS-LuxR family regulator $\mathrm{CfaR}$ in the common scab pathogen Streptomyces scabies. PLoS One 10: e0122450.

Du, Y. L., Shen, X. L., Yu, P., Bai, L. Q., and Li, Y. Q. 2011. Gammabutyrolactone regulatory system of Streptomyces chattanoogensis links nutrient utilization, metabolism, and development. Appl. Environ. Microbiol. 77:8415-8426.

Duda, D. M., Walden, H., Sfondouris, J., and Schulman, B. A. 2005. Structural analysis of Escherichia coli ThiF. J. Mol. Biol. 349:774-786.

Duval, I., and Beaudoin, N. 2009. Transcriptional profiling in response to inhibition of cellulose synthesis by thaxtomin A and isoxaben in Arabidopsis thaliana suspension cells. Plant Cell Rep. 28:811-830.

Felsenstein, J. 1985. Confidence limits on phylogenies: An approach using the bootstrap. Evolution 39:783-791.

Fry, B., and Loria, R. 2002. Thaxtomin A: Evidence for a plant cell wall target. Physiol. Mol. Plant Pathol. 60:1-8.

Fyans, J. K., Altowairish, M. S., Li, Y., and Bignell, D. R. D. 2015. Characterization of the coronatine-like phytotoxins produced by the common scab pathogen Streptomyces scabies. Mol. Plant-Microbe Interact 28:443-454.

Fyans, J. K., Bown, L., and Bignell, D. R. D. 2016. Isolation and characterization of plant-pathogenic Streptomyces species associated with common scab-infected potato tubers in Newfoundland. Phytopathology 106:123-131.
Geng, X., Cheng, J., Gangadharan, A., and Mackey, D. 2012. The coronatine toxin of Pseudomonas syringae is a multifunctional suppressor of Arabidopsis defense. Plant Cell 24:4763-4774.

Geng, X., Jin, L., Shimada, M., Kim, M. G., and Mackey, D. 2014. The phytotoxin coronatine is a multifunctional component of the virulence armament of Pseudomonas syringae. Planta 240:1149-1165.

Goyer, C., Vachon, J., and Beaulieu, C. 1998. Pathogenicity of Streptomyces scabies mutants altered in thaxtomin A production. Phytopathology 88:442-445.

Gust, B., O'Rourke, S., Bird, N., Kieser, T., and Chater, K. 2003 Recombineering in Streptomyces coelicolor. The John Innes Foundation, Norwich, U.K

Healy, F. G., Wach, M., Krasnoff, S. B., Gibson, D. M., and Loria, R. 2000 The $t x t A B$ genes of the plant pathogen Streptomyces acidiscabies encode a peptide synthetase required for phytotoxin thaxtomin A production and pathogenicity. Mol. Microbiol. 38:794-804.

Hershko, A., and Ciechanover, A. 1998. The ubiquitin system. Annu. Rev. Biochem. 67:425-479.

Hill, J., and Lazarovits, G. 2005. A mail survey of growers to estimate potato common scab prevalence and economic loss in Canada. Can. J. Plant Pathol. 27:46-52.

Hiltunen, L. H., Weckman, A., Ylhainen, A., Rita, H., Richter, E., and Valkonen, J. P. T. 2005. Responses of potato cultivars to the common scab pathogens, Streptomyces scabies and S. turgidiscabies. Ann. Appl. Biol. 146:395-403.

Horbal, L., Rebets, Y., Rabyk, M., Makitrynskyy, R., Luzhetskyy, A., Fedorenko, V., and Bechthold, A. 2012. SimReg1 is a master switch for biosynthesis and export of simocyclinone D8 and its precursors. AMB Express 2:1.

Itzen, A., Blankenfeldt, W., and Goody, R. S. 2011. Adenylylation: Renaissance of a forgotten post-translational modification. Trends Biochem. Sci. 36:221-228

Jiang, H., and Hutchinson, C. R. 2006. Feedback regulation of doxorubicin biosynthesis in Streptomyces peucetius. Res. Microbiol. 157:666-674.

Johnson, E. G., Joshi, M. V., Gibson, D. M., and Loria, R. 2007. Cellooligosaccharides released from host plants induce pathogenicity in scabcausing Streptomyces species. Physiol. Mol. Plant. Pathol. 71:18-25.

Johnson, E. G., Krasnoff, S. B., Bignell, D. R. D., Chung, W. C., Tao, T., Parry, R. J., Loria, R., and Gibson, D. M. 2009. 4-Nitrotryptophan is a substrate for the non-ribosomal peptide synthetase TxtB in the thaxtomin A biosynthetic pathway. Mol. Microbiol. 73:409-418.

Jones, D. T., Taylor, W. R., and Thornton, J. M. 1992. The rapid generation of mutation data matrices from protein sequences. Comput. Appl. Biosci. $8: 275-282$

Katsir, L., Chung, H. S., Koo, A. J., and Howe, G. A. 2008. Jasmonate signaling: A conserved mechanism of hormone sensing. Curr. Opin. Plant Biol. 11:428-435.

Kieser, T., Bibb, M. J., Buttner, M. J., Chater, K. F., and Hopwood, D. A 2000. Practical Streptomyces. Genetics. The John Innes Foundation, Norwich, U.K.

King, R. R., and Calhoun, L. A. 2009. The thaxtomin phytotoxins: Sources, synthesis, biosynthesis, biotransformation and biological activity. Phytochemistry 70:833-841.

King, R. R., Lawrence, C. H., and Clark, M. C. 1991. Correlation of phytotoxin production with pathogenicity of Streptomyces scabies isolates from scab infected potato tubers. Am. Potato J. 68:675-680.

Kinkel, L. L., Bowers, J. H., Shimizu, K., Neeno-Eckwall, E. C., and Schottel, J. L. 1998. Quantitative relationships among thaxtomin A production, potato scab severity, and fatty acid composition in Streptomyces. Can. J. Microbiol. 44:768-776.

Kutas, P., Feckova, L., Rehakova, A., Novakova, R., Homerova, D. Mingyar, E., Rezuchova, B., Sevcikova, B., and Kormanec, J. 2013 Strict control of auricin production in Streptomyces aureofaciens CCM 3239 involves a feedback mechanism. Appl. Microbiol. Biotechnol. 97: 2413-2421.

Lehmann, C., Begley, T. P., and Ealick, S. E. 2006. Structure of the Escherichia coli ThiS-ThiF complex, a key component of the sulfur transfer system in thiamin biosynthesis. Biochemistry 45:11-19.

Leimkühler, S., Wuebbens, M. M., and Rajagopalan, K. V. 2001. Characterization of Escherichia coli MoeB and its involvement in the activation of molybdopterin synthase for the biosynthesis of the molybdenum cofactor. J. Biol. Chem. 276:34695-34701

Li, J., Li, Y., Niu, G., Guo, H., Qiu, Y., Lin, Z., Liu, W., and Tan, H. 2018. NosP-regulated nosiheptide production responds to both peptidyl and small-molecule ligands derived from the precursor peptide. Cell Chem. Biol. 25:143-153.e4

Li, Q., Wang, L., Xie, Y., Wang, S., Chen, R., and Hong, B. 2013. SsaA, a member of a novel class of transcriptional regulators, controls 
sansanmycin production in Streptomyces sp. strain SS through a feedback mechanism. J. Bacteriol. 195:2232-2243.

Loria, R., Bignell, D. R. D., Moll, S., Huguet-Tapia, J. C., Joshi, M. V., Johnson, E. G., Seipke, R. F., and Gibson, D. M. 2008. Thaxtomin biosynthesis: The path to plant pathogenicity in the genus Streptomyces. Antonie van Leeuwenhoek 94:3-10.

Loria, R., Bukhalid, R. A., Creath, R. A., Leiner, R. H., Olivier, M., and Steffens, J. C. 1995. Differential production of thaxtomins by pathogenic Streptomyces species in vitro. Phytopathology 85:537-541.

MacNeil, D. J., Gewain, K. M., Ruby, C. L., Dezeny, G., Gibbons, P. H., and MacNeil, T. 1992. Analysis of Streptomyces avermitilis genes required for avermectin biosynthesis utilizing a novel integration vector. Gene 111:61-68.

Mao, X. M., Sun, Z. H., Liang, B. R., Wang, Z. B., Feng, W. H., Huang, F. L., and Li, Y. Q. 2013. Positive feedback regulation of $s t g R$ expression for secondary metabolism in Streptomyces coelicolor. J. Bacteriol. 195: 2072-2078.

Mast, Y., Guezguez, J., Handel, F., and Schinko, E. 2015. A complex signaling cascade governs pristinamycin biosynthesis in Streptomyces pristinaespiralis. Appl. Environ. Microbiol. 81:6621-6636.

Niu, G., Chater, K. F., Tian, Y., Zhang, J., and Tan, H. 2016. Specialised metabolites regulating antibiotic biosynthesis in Streptomyces spp. FEMS Microbiol. Rev. 40:554-573.

Regni, C. A., Roush, R. F., Miller, D. J., Nourse, A., Walsh, C. T., and Schulman, B. A. 2009. How the MccB bacterial ancestor of ubiquitin E1 initiates biosynthesis of the microcin C7 antibiotic. EMBO J. 28: 1953-1964.

Roush, R. F., Nolan, E. M., Löhr, F., and Walsh, C. T. 2008. Maturation of an Escherichia coli ribosomal peptide antibiotic by ATP-consuming N-P bond formation in microcin C7. J. Am. Chem. Soc. 130:3603-3609.

Roy, A., Yang, J., and Zhang, Y. 2012. COFACTOR: An accurate comparative algorithm for structure-based protein function annotation. Nucleic Acids Res. 40:W471-W477.

Sambrook, J., and Russell, D. W. 2001. Molecular Cloning: A Laboratory Manual, 3rd Ed. Cold Spring Harbor Laboratory Press, Cold Spring Harbor, NY, U.S.A.

Scheible, W. R., Fry, B., Kochevenko, A., Schindelasch, D., Zimmerli, L., Somerville, S., Loria, R., and Somerville, C. R. 2003. An Arabidopsis mutant resistant to thaxtomin A, a cellulose synthesis inhibitor from Streptomyces species. Plant Cell 15:1781-1794.

Schneider, C. A., Rasband, W. S., and Eliceiri, K. W. 2012. NIH Image to ImageJ: 25 years of image analysis. Nat. Methods 9:671-675.

Shepherd, M. D., Kharel, M. K., Bosserman, M. A., and Rohr, J. 2010. Laboratory maintenance of Streptomyces species. Curr. Protoc. Microbiol. 18:10E.1.1-10E.1.8.

Spitaler, M., Villunger, A., Grunicke, H., and Uberall, F. 2000. Unique structural and functional properties of the ATP-binding domain of atypical protein kinase C-iota. J. Biol. Chem. 275:33289-33296.
Tahlan, K., Ahn, S. K., Sing, A., Bodnaruk, T. D., Willems, A. R. Davidson, A. R., and Nodwell, J. R. 2007. Initiation of actinorhodin export in Streptomyces coelicolor. Mol. Microbiol. 63:951-961.

Tamura, K., Peterson, D., Peterson, N., Stecher, G., Nei, M., and Kumar, S. 2011. MEGA5: Molecular evolutionary genetics analysis using maximum likelihood, evolutionary distance, and maximum parsimony methods. Mol. Biol. Evol. 28:2731-2739.

Taylor, B. L., and Zhulin, I. B. 1999. PAS domains: Internal sensors of oxygen, redox potential, and light. Microbiol. Mol. Biol. Rev. 63: 479-506.

Taylor, S. V., Kelleher, N. L., Kinsland, C., Chiu, H. J., Costello, C. A., Backstrom, A. D., McLafferty, F. W., and Begley, T. P. 1998. Thiamin biosynthesis in Escherichia coli. Identification of ThiS thiocarboxylate as the immediate sulfur donor in the thiazole formation. J. Biol. Chem. 273:16555-16560.

Vander Horn, P. B., Backstrom, A. D., Stewart, V., and Begley, T. P. 1993. Structural genes for thiamine biosynthetic enzymes (thiCEFGH) in Escherichia coli K-12. J. Bacteriol. 175:982-992.

Wanner, L. A., and Kirk, W. W. 2015. Streptomyces-From basic microbiology to role as a plant pathogen. Am. J. Potato Res. 92:236-242.

Wilson, C. R. 2004. A summary of common scab disease of potato research from Australia. Proceeedings of the Intgernational Potato Scab Symposium 2004, Hokkaido University, Sapporo, Japan.

Xi, J., Ge, Y., Kinsland, C., McLafferty, F. W., and Begley, T. P. 2001 Biosynthesis of the thiazole moiety of thiamin in Escherichia coli Identification of an acyldisulfide-linked protein-Protein conjugate that is functionally analogous to the ubiquitin/E1 complex. Proc. Natl. Acad. Sci. U.S.A. 98:8513-8518.

Xin, X. F., and He, S. Y. 2013. Pseudomonas syringae pv. tomato DC3000: A model pathogen for probing disease susceptibility and hormone signaling in plants. Annu. Rev. Phytopathol. 51:473-498.

Xu, G., Wang, J., Wang, L., Tian, X., Yang, H., Fan, K., Yang, K., and Tan, H. 2010. "Pseudo" $\gamma$-butyrolactone receptors respond to antibiotic signals to coordinate antibiotic biosynthesis. J. Biol. Chem. 285: 27440-27448.

Yang, J., Roy, A., and Zhang, Y. 2013. Protein-ligand binding site recognition using complementary binding-specific substructure comparison and sequence profile alignment. Bioinformatics 29:25882595 .

Zhang, C., Freddolino, P. L., and Zhang, Y. 2017. COFACTOR: Improved protein function prediction by combining structure, sequence and protein-protein interaction information. Nucleic Acids Res. 45 (W1): W291-W299.

Zhang, Y. 2008. I-TASSER server for protein 3D structure prediction. BMC Bioinformatics 9:40.

Zhang, Y., Pan, G., Zou, Z., Fan, K., Yang, K., and Tan, H. 2013. JadR*mediated feed-forward regulation of cofactor supply in jadomycin biosynthesis. Mol. Microbiol. 90:884-897. 